\title{
Trajectory-based Combustion Control for Renewable Fuels in Free Piston Engines
}

Chen Zhang, Zongxuan Sun ${ }^{1}$

Department of Mechanical Engineering, University of Minnesota, Twin Cities Campus, 111 Church Street SE, Minneapolis, MN 55455

\begin{abstract}
Previously, the authors have developed an advanced combustion control, namely the trajectory-based combustion control, to further leverage the flexibility of free piston engine (FPE). With the assistance of this control method, the FPE enables optimization of both engine efficiency and emissions by implementing optimal piston trajectories. Extensive simulations have been conducted to prove the effectiveness of this combustion control on fossil fuels. In this paper, the investigation is extended to renewable fuels. Seven renewable fuels are considered herein including hydrogen, biogas, syngas, ethanol, dimethyl ether (DME), biodiesel, and Fischer-Tropsch fuel. The influences of both compression ratio $(C R)$ and piston motion pattern between the two dead centers on the combustion process are considered in the study, which demonstrates the ultimate fuel flexibility and large tolerance of fuel impurity possessed by the FPE. In addition, the simulation results show that at a fixed CR, the thermal efficiency of the FPE can still be enhanced (5\% in DME case) by varying the piston motion patterns alone. Furthermore, specific asymmetric piston trajectories are synthesized to further improve the engine thermal efficiency ( $8 \%$ in hydrogen case) and reduce the NOx emission simultaneously (around $70 \%$ reduction in hydrogen case). In other words, due to its ultimate fuel flexibility, large tolerance of fuel impurity, and controllable piston trajectory, the FPE, with the trajectory-based combustion control, enables a co-optimization of renewable fuels and engine operation.
\end{abstract}

Keywords: Renewable fuels, Free piston engine, Trajectory-based combustion control.

\footnotetext{
${ }^{1}$ Corresponding author. Tel.: +01 612-625-2107

E-mail address: zsun@umn.edu (Zongxuan Sun)
}

(c) 2016. This manuscript version is made available under the Elsevier user license

http://www.elsevier.com/open-access/userlicense/1.0/ 


\section{Introduction}

Currently, transportation sector alone consumes about $30 \%$ of the total energy in the USA [1]. Almost $95 \%$ of this energy comes from petroleum-based fuels $[1,2]$. This situation raises two concerns: energy sources depletion and environmental impact: as projected, the worldwide oil reserves can only sustain 40 50 years at current consumption rate. Meanwhile, almost $14 \%$ global greenhouse gas (GHG) emissions are produced due to the combustion of fossil fuels in transportation sector [3]. Such crisis will be even more exacerbated due to the rapid growth of energy demands for transportation in the future [4]. Consequently, lots of automotive technologies are proposed, and adopting renewable fuels is one of them. Such an introduction certainly increases the diversity of energy sources. In addition, based on the life cycle assessment (LCA) of renewable fuels, the GHG emission is also reduced significantly since their feedstock production are mainly via the photosynthesis process, which absorbs a large amount of $\mathrm{CO}_{2}$ from the atmosphere. [2, 5-11].

However, widely implementation of renewable fuels in automobiles still remains elusive to date, mainly caused by its high cost. Such a high cost comes from two aspects: One is the feedstock price and the other one is the processing expenditure, which is spent to convert the feedstock to available fuels for conventional internal combustion engine (ICE). Currently, mature technologies producing renewable fuels, e.g. ethanol and biodiesel, require valuable crops or animal fats as the feedstock, which raises lots of public concerns due to the shortage of food for increasing global population [12]. As a result, low cost feedstock, such as lignocellulose, algae, waste vegetable oil, and municipal solid waste are then proposed. However, these feedstock inevitably increase the processing expenditure, since they require complicated pretreatments and purification processes.

The above trade-off makes it difficult to reduce the renewable fuel price thoroughly. However, this dilemma stems from a plausible fact that all renewable fuels have to possess similar physical and chemical properties as gasoline or diesel. This premise significantly constrains the research on renewable fuels. Consequently, the majority of related research only focus on synthesizing the so-called drop-in renewable fuels [13], rather than producing optimal alternative fuels, which power vehicles more effectively and cleanly at lower costs. It is possible that conventional ICE is not suitable for such optimal renewable fuels, due to their different physical and chemical properties compared to gasoline or diesel. Therefore, a new flexible engine is desired to leverage these renewable fuels.

Free piston engine (FPE) is such a flexible engine [14-21]. Due to the absence of the mechanical crankshaft, the FPE owns ultimate freedom on its piston motion and enables variable compression ratio (CR). As a result, different fuels can be employed in the FPE, without any mechanism modification [22]. Figure 1 shows the FPE at the University of Minnesota.

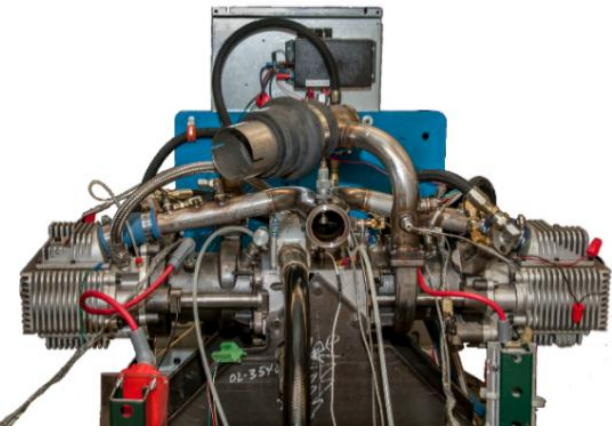

(a)

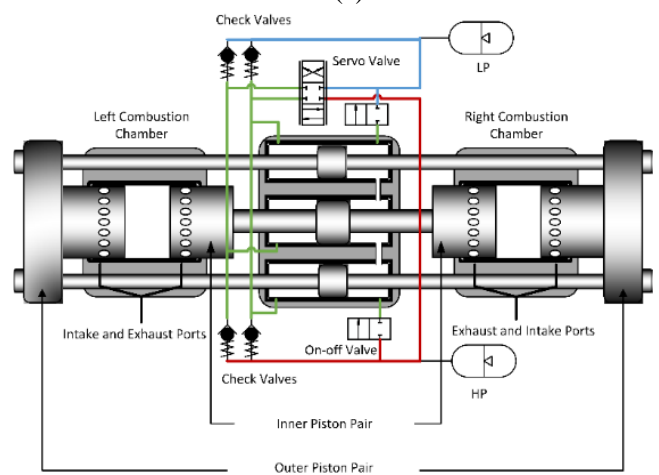

(b)

Figure 1. Picture (a) and schematic (b) of the FPE at the UMN

As can be seen, two combustion chambers are located at two ends of the engine, and combustion will occur inside each chamber alternatively. Consequently, the combustion forces will push the piston moving back and force and generate fluid power through this linear piston motion. The main technical barrier of FPE is the lack of precise and robust piston motion control, since its piston movement is completely determined by combustion force and load dynamics in real-time [19, 20, 23-25]. Previously, an active piston motion control, namely the "virtual crankshaft", has been developed and implemented into the FPE. With the assistance of this advanced control, the FPE enables its piston to track any prescribed trajectories reference precisely $[19,20]$. The FPE's specification is listed in Table. 1.

\section{Specification}

Table. 1 Specification of hydraulic free piston engine

\section{Bore}

Nominal Stroke

Displacement/cylinder

Number of cylinders

Inner plunger diameter

Outer plunger diameter

Total hydraulic plunger area

Besides variable $\mathrm{CR}$, the controllable piston trajectory also provides an additional control means to tailor the combustion process and therefore improves the engine performances. This capability forms the concept of trajectorybased combustion control [26, 27]. As shown in Fig. 2, the combustion inside the engine, especially for HCCI mode, is determined by the interaction between the fuel chemical kinetics and the in-cylinder gas dynamics through a feedback manner. Traditional control methods in conventional ICE can only affect this interaction at specific time instants within an engine cycle, rather than adjust it in real time. However, with the virtual crankshaft, an optimal piston trajectory can be 
designed and implemented into the FPE, which effectively controls the combustion process via varying combustion chamber volumes profiles. In this way, the engine efficiency can be improved significantly, while the emissions are reduced simultaneously.

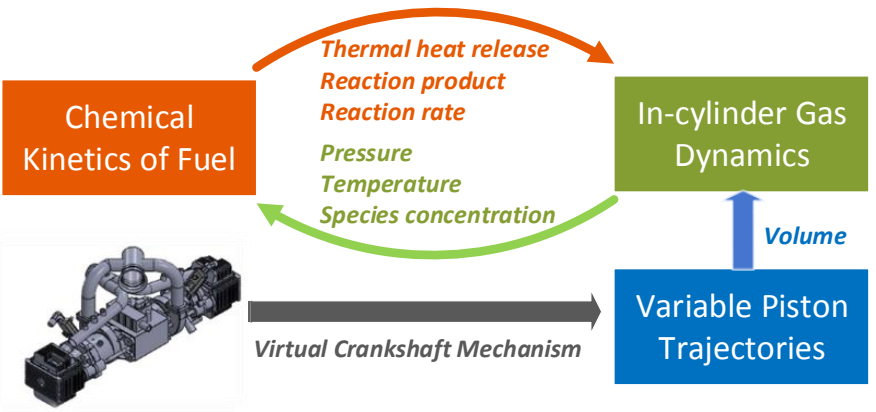

Figure 2. Interaction between chemical kinetics and gas dynamics

The effectiveness of the trajectory-based HCCI combustion for fossil fuels has been presented previously [26, 27]. In this paper, this advanced combustion control is applied to renewable fuels, which shows advantages in terms of ultimate fuel flexibility, large tolerance of fuel impurities and comprehensive engine performance improvement. The rest of this paper is structured as follow: first of all, a review of seven selected renewable fuels is presented. Afterward, a comprehensive model, describing the FPE operation under HCCI combustion, is presented. Then the corresponding simulation results are discussed. At last, the conclusions as well as potential future works, is presented.

\section{Renewable Fuels}

Renewable fuels are referred to gaseous or liquid fuels converted from sustainable feedstock. Typical renewable fuels nowadays include hydrogen, biogas, syngas, ethanol, DME, biodiesel, and F-T fuel. The physical and chemical properties of these seven fuels are listed in Table. 2 for comparison. In the rest of this section, a comprehensive review is presented, which discusses properties, production technologies and existing challenges of each fuels in detail.

\subsection{Hydrogen}

Hydrogen $\left(\mathrm{H}_{2}\right)$ is the lightest element, which results in some extreme properties, such as high thermal conductivity, rapid burning speed, and quite a high octane number [8]. As a fuel, $\mathrm{H}_{2}$ has the highest energy content per unit of mass, around $120 \mathrm{MJ} / \mathrm{kg}$, and produces zero C-based emissions. Additionally, since $\mathrm{H}_{2}$ is the most plentiful element on earth, it is also considered as one of the endless energy sources.

Currently, extensive researches have been conducted to investigate the production of $\mathrm{H}_{2}$ from biomass directly. Those processes are usually classified into two groups: thermalchemical conversion and bio-chemical conversion [28]. The former approach involves a series of thermal chemical reactions, such as steam reforming, pyrolysis, and gasification of biomass. The latter one includes fermentative $\mathrm{H}_{2}$ production, photosynthesis process, and biological water gas shift reaction [29]. Even though it is more environmental friendly and less energy intensive, the bio-chemical conversion still needs to further improve its conversion efficiency and decrease the related cost [9]. In addition, $\mathrm{H}_{2}$ can also be produced via water

Table. 2 Properties of seven renewable fuels, gasoline and diesel $[2-8,10,11]$

\begin{tabular}{|c|c|c|c|c|c|c|c|c|c|c|}
\hline Property & Unit & $\mathbf{H}_{2}$ & Biogas & Syngas & Ethanol & DME & Biodiesel & F-T fuels & Gasoline & Diesel \\
\hline Molar mass & $\mathrm{g} / \mathrm{mol}$ & 2 & $\sim 22$ & $\sim 25$ & 46 & 46 & $\sim 290$ & $\sim 210$ & $\sim 110$ & $\sim 170$ \\
\hline C content & Mass \% & 0 & $\sim 44$ & $\sim 14$ & 52.2 & 52.2 & $\sim 77$ & 85.7 & 84 & 86 \\
\hline$H$ content & Mass $\%$ & 100 & $\sim 10$ & $\sim 2$ & 13 & 13 & $\sim 12$ & 14.3 & 16 & 14 \\
\hline O Content & Mass $\%$ & 0 & $\sim 46$ & $\sim 24$ & 34.8 & 34.8 & $\sim 11$ & 0 & 0 & 0 \\
\hline Density & $\mathrm{kg} / \mathrm{m}^{3}$ & 0.082 & $\sim 1.15$ & $\sim 0.95$ & 785 & 667 & 880 & 757 & 737 & 831 \\
\hline Cetane number & & $<0$ & $<0$ & $<0$ & $5-8$ & $>55$ & 47 & $>70$ & $0-5$ & $40-50$ \\
\hline Auto-ignition Temperature & ${ }^{\circ} \mathrm{C}$ & 500 & $>600$ & $>600$ & 365 & 350 & 370 & - & 260 & 210 \\
\hline Low heating value & $\mathrm{MJ} / \mathrm{kg}$ & 120 & $\sim 30$ & $\sim 18$ & 26.87 & 27.6 & $\sim 37$ & 43.24 & 43.47 & 42.5 \\
\hline Kinematic viscosity & $\mathrm{cSt}$ & $\sim 100$ & - & - & $1.1-2.2$ & $<0.1$ & $1.9-6.0$ & - & $<1$ & 3 \\
\hline Boiling point & $\mathrm{K}$ & 20 & $\sim 150$ & $\sim 100$ & 351 & 248.1 & 360 & - & $310-478$ & $450-643$ \\
\hline Vapor pressure (at 298K) & $\mathrm{kPa}$ & - & - & - & 5.83 & 530 & $<10$ & - & $<180$ & $<<10$ \\
\hline
\end{tabular}

132 electrolysis, which is more sustainable, if renewable energy,

such as solar energy, wind turbine, and hydropower plant, are employed.

There are some roadblocks preventing the large scale utilization of $\mathrm{H}_{2}$. The most severe problem is the safety of $\mathrm{H}_{2}$ storage and transportation. Due to its small molecular size and less ignition energy, $\mathrm{H}_{2}$ could easily be dispersed into the atmosphere and ignited [8].

\subsection{Biogas}

Biogas is a versatile gaseous renewable energy source, which is predominantly produced by anaerobic digestion (AD) of energy crops, agriculture residues, livestock waste, industry slurry and municipal solid waste. The main components of raw biogas are $\mathrm{CH}_{4}, 50-70 \%$ in vol., and $\mathrm{CO}_{2}, 30-40 \%$ in vol., with a smaller amount of $\mathrm{H}_{2} \mathrm{~S}$ and $\mathrm{NH}_{3}$ [30]. Due to the large amount of $\mathrm{CO}_{2}$, the raw biogas has smaller lower heating value and much larger density compared to natural gas.
As one of the most energy-efficient and environmentfriendly renewable fuels, the production of biogas through AD offers unbeatable benefits compared to the others. For example, extremely low cost of feedstock decreases its price significantly; the AD process provides an excellent approach dealing with the landfill deposit and waste recovery, and therefore improving human health and hygiene. As a result, more countries have explored the utilization of biogas since last century: The United States consumed 147 trillion BTU (155 trillion $\mathrm{kJ}$ ) of energy from biogas, about $0.6 \%$ of the national natural gas consumption in 2003 [31]. In 2008, more than $60 \%$ of gaseous vehicle fuel in Sweden is biogas, which powered more than 17,000 vehicles nationally [32]. At the end of 2010, almost 6,000 biogas plants were operated in German [33].

Usually, the raw biogas is used in combined heat and power (CHP) plant after desulfurization and dehydration. In 
166 addition, the raw biogas can also be upgraded by 167 concentrating the methane component up to $95 \%$ or more [34]. 168 The upgraded biogas, or so-called bio-methane, is widely 169 adopted as the vehicle fuels in many European countries, such 170 as Germany, Sweden, Switzerland, and Norway. However, the 171 upgrading process inevitably increases the price of biogas and 172 limits its market. Other related technological issues also exist 173 including the methane slip problem during the upgrading 174 process and its transportation challenges.

\section{2.3. Syngas}

Syngas is another gaseous fuel which is converted via gasification, a thermochemical conversion process which partially oxidizes hydrocarbon compounds into different products [35]. Typically, the produced syngas contains multiple gases, such as $\mathrm{CO}, \mathrm{H}_{2}, \mathrm{CH}_{4}, \mathrm{CO}_{2}$ and $\mathrm{N}_{2}$. Other impurities, such as tar, particulate matter (PM) and char, also exist. The main chemical reactions governing the conversion process can be summarized as follow:

Partial oxidation:

$$
\mathrm{C}+0.5 \mathrm{O}_{2} \leftrightarrow \mathrm{CO}
$$

Complete oxidation:

$\mathrm{C}+\mathrm{O}_{2} \leftrightarrow \mathrm{CO}_{2}$

Water gas reaction:

$$
\mathrm{C}+\mathrm{H}_{2} \mathrm{O} \leftrightarrow \mathrm{CO}+\mathrm{H}_{2}
$$

Water gas shift reaction:

$$
\mathrm{CO}+\mathrm{H}_{2} \mathrm{O} \leftrightarrow \mathrm{CO}_{2}+\mathrm{H}_{2}
$$

Methane formation:

$$
\mathrm{CO}+3 \mathrm{H}_{2} \leftrightarrow \mathrm{CH}_{4}+\mathrm{H}_{2} \mathrm{O}
$$

Currently, gasification is recognized as the most promising technology to be fully commercialized. The gasifiers can be categorized into two groups: fixed bed gasifier and fluidized bed gasifier. The dominant gasifier is the fixed bed downdraft one due to its higher conversion efficiencies and lower production of tar and PM [36]. Typical compositions of syngas from this gasifier are listed in Table. 3

Table. 3 Typical bio-syngas composition produced from downdraft gasifiers operated on low- to medium moisture content feedstock [37]
Component

$\begin{array}{cc}\mathrm{H}_{2} & 12-20 \\ \mathrm{CO}_{2} & 9-15 \\ \mathrm{CH}_{4} & 2-3 \\ \mathrm{CO} & 17-22 \\ \mathrm{~N}_{2} & 50-54\end{array}$

Increasing $\mathrm{CR}$ is an effective way to address this issue. It has been demonstrated that a 15-20\% improvement of power derating could be achieved if high CR engine is utilized [38].

\subsection{Ethanol}

Ethanol is mainly produced from renewable biomass through the fermentation process. It has been accepted as a fuel for ICE even before the gasoline [39]. Currently, ethanol is still a promising alternatives fuel due to its compatibility of existing ICE. Besides, ethanol has a higher octane number, which enables the ICE to operate at higher CR [10]. The utilization of ethanol in the ICE can also reduce emissions, e.g. $\mathrm{CO}$, unburned $\mathrm{HC}, \mathrm{SO}_{\mathrm{x}}$ and $\mathrm{NO}_{\mathrm{x}}$, due to its higher oxygen content, almost zero sulfur content and less lower heating value (LHV) [39].

The production of ethanol is drastically increased from 4.5 billion gallons to 23.4 billion gallons in 2010 globally [40]. Conventionally, ethanol is produced from the food crops, which are easily transformed to simple sugar through milling, liquefaction, and saccharification. Then, the simple sugar is further fermented to ethanol via specific microorganisms. The corresponding chemical process is represented as follow:

$$
\begin{gathered}
\left(\mathrm{C}_{6} \mathrm{H}_{10} \mathrm{O}_{5}\right)_{n}(\text { sugar, cellulose })+n \mathrm{H}_{2} \mathrm{O} \rightarrow n \mathrm{C}_{6} \mathrm{H}_{12} \mathrm{O}_{6} \\
\mathrm{C}_{6} \mathrm{H}_{12} \mathrm{O}_{6} \rightarrow 2 \mathrm{CH}_{3} \mathrm{CH}_{2} \mathrm{OH}(\text { ethanol })+2 \mathrm{CO}_{2}
\end{gathered}
$$

Concerns are raised for this approach due to the food supply issues worldwide. Therefore, conversion of ethanol from the non-food lignocellulosic plant, or so-called "second generation feedstock", is extensively explored [5]. Consequently, besides reactions (6) and (7), the conversion process of second generation feedstock is also affected by following reactions:

$$
\begin{gathered}
\left.\left(\mathrm{C}_{5} \mathrm{H}_{8} \mathrm{O}_{4}\right)_{n} \text { (hemicellulose }\right)+n \mathrm{H}_{2} \mathrm{O} \rightarrow n \mathrm{C}_{5} \mathrm{H}_{10} \mathrm{O}_{5} \\
3 \mathrm{C}_{5} \mathrm{H}_{10} \mathrm{O}_{5} \rightarrow 5 \mathrm{CH}_{3} \mathrm{CH}_{2} \mathrm{OH}(\text { ethanol })+5 \mathrm{CO}_{2}
\end{gathered}
$$

To date, how to extract simple sugar from these lignocellulosic materials in a cost-effective way, is still a bottleneck for this technology. Usually, such feedstock has been treated through acid hydrolysis and/or enzymatic hydrolysis before the fermentation process [5], which are very energy- and cost-intensive. Other conversion methods, e.g. thermochemical transformation of lignocellulosic materials and ethanol production from microalgae and seaweeds, are also proposed, which have not entered into practice yet.

\subsection{Dimethyl ether (DME)}

DME is the simplest ether with a chemical formula of $\mathrm{CH}_{3} \mathrm{OCH}_{3}$. Its physical properties are quite similar to other liquefied petroleum-based gas, such as propane and butane. DME is usually compressed to the liquid phase and works as a substitute for diesel fuel [5-7]. At the present time, most DME is produced by dehydrogenation of methanol from natural gas or syngas:

Methanol synthesis: $\quad \mathrm{CO}+2 \mathrm{H}_{2} \leftrightarrow \mathrm{CH}_{3} \mathrm{OH}$

Methanol dehydration: $2 \mathrm{CH}_{3} \mathrm{OH} \leftrightarrow \mathrm{CH}_{3} \mathrm{OCH}_{3}+\mathrm{H}_{2} \mathrm{O}$

Water-gas shift:

$$
\begin{aligned}
& \mathrm{H}_{2} \mathrm{O}+\mathrm{CO} \leftrightarrow \mathrm{H}_{2}+\mathrm{CO}_{2} \\
& 3 \mathrm{H}_{2}+3 \mathrm{CO} \leftrightarrow \mathrm{CH}_{3} \mathrm{OCH}_{3}+\mathrm{CO}_{2}
\end{aligned}
$$

Net reaction: 
- Human Health: DME is accepted as a non-toxic and noncarcinogenic volatile organic compound.

- Economy: due to its similar properties of liquefied petroleum gas, DME can use the existing gas infrastructures for transport and storage.

- Environment impact: The absence of C-C bond in DME and its high oxygen content result in less PM and NOx.

Nonetheless, the relatively lower heating value of DME requires the ICE operating at a higher CR to fully extract its chemical energy. Meanwhile, the existence of multiple impurities, such as methanol and water, also asks for specific treatment before it is feed to conventional ICE.

\subsection{Biodiesel}

Biodiesel is a yellowish liquid whose chemical structure is mainly mono-alkyl esters of fatty acids [5]. It is considered as one of the best non-toxic and bio-degradable drop-in biofuels. From 2003 to 2013, the worldwide production of biodiesel has increased significantly, from 213 million gallons to 6289 million gallons [41].

At the very beginning, the biodiesel was produced from vegetable oil or animal fat directly by mechanical extraction. However, mainly due to the high viscosity of the derived oil, it was abandoned. Afterwards, many alternative approaches, e.g. blending, micro-emulsions and transesterification, were proposed [42]. At the present time, the dominant technology is transesterification, governed by reaction (14), where $R_{l}, R_{2}$ and $R_{3}$ are different or the same aliphatic hydrocarbon groups $[5]$.

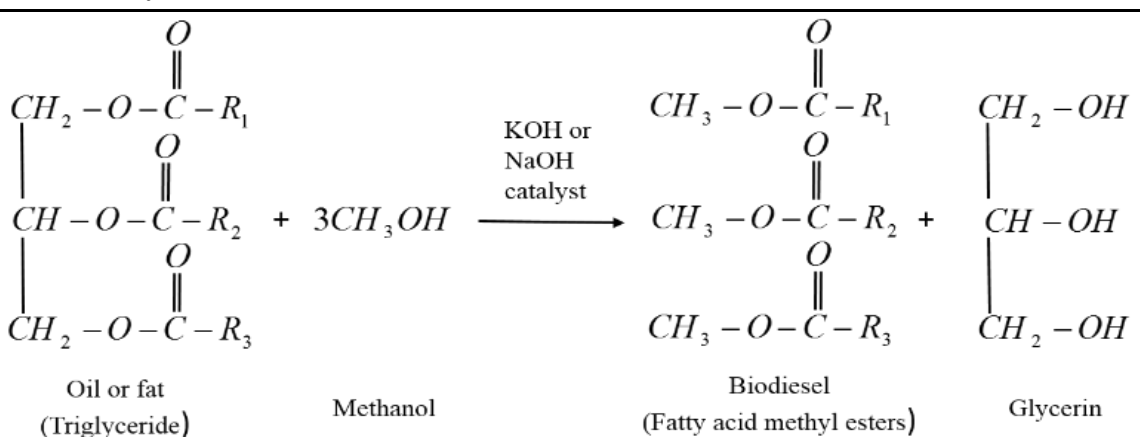

Even though the properties of produced bio-diesel are excellent, the high cost of the corresponding feedstock, such as vegetable oil and animal fat, still prevents the transesterification from wide commercialization. This drawback results in the exploration of the second generation feedstock, including used vegetable oil, non-edible plant oils, and even waste restaurant oil $[2,5]$. Due to the high content of free fatty acid in those second generation feedstock, the corresponding production technologies are also upgraded. The third generation feedstock, such as algae, bacilli, fungi, and yeast [8], are also proposed to further reduce bio-diesel price. Nonetheless, lots of challenges still exist for the third generation feedstock in terms of cost and efficiency.

It is widely accepted that bio-diesel can be injected into the diesel engine directly, with no or minor hardware modification. Even though the fuel economy may reduce around $10 \%$ due to its less low heating value [13], the emissions performance, in terms of SOx, NOx, and PM, is much better than its petroleum-based counterparts [43].

\subsection{Fisher-Tropsch fuels}

Fisher-Tropsch fuel, or F-T fuel, is the name of a variety of liquid hydrocarbons which are produced from syngas through Fisher-Tropsch synthesis, established by Germany scientists, Franz Fisher and Hans Tropsch, back to 1920s [44]:

$$
\begin{aligned}
& n \mathrm{CO}+2 n \mathrm{H}_{2} \rightarrow\left(-\mathrm{CH}_{2}-\right)+n \mathrm{H}_{2} \mathrm{O} \\
& n \mathrm{CO}+(2 n+1) \mathrm{H}_{2} \rightarrow \mathrm{C}_{n} \mathrm{H}_{2 n+2}+n \mathrm{H}_{2} \mathrm{O} \\
& n \mathrm{CO}+(n+m / 2) \mathrm{H}_{2} \rightarrow \mathrm{C}_{n} \mathrm{H}_{m}+n \mathrm{H}_{2} \mathrm{O}
\end{aligned}
$$

As can be seen, the production of F-T fuels can be separated into three steps: syngas generation, syngas processing and finally Fischer-Tropsch synthesis. It was evaluated that the syngas generation, especially from the biomass, accounts for more than half of the capital investment and operating cost [45]. Variable aspects affect the yield and quality of the F-T fuels, including reaction temperature, reaction pressure, feed gas composition and catalyst type.

Since its majority components are straight-chain alkanes, the F-T fuels own very high quality as a substitute for diesel fuel. In addition, attributed to its relatively $\mathrm{S}$-free content and few aromatic compounds, the F-T fuels generate nearly zero SOx and PM emissions. Furthermore, due to its high cetane number, the F-T fuels can also be blended into traditional diesel to further improve its quality.

\section{Model Approach}

By leveraging the ultimate flexibility of piston motion in the FPE, all the selected renewable fuels are assumed to undergo HCCI combustion mode, which is one of the most promising low temperature combustion technologies to provide high thermal efficiency and reduce emissions significantly. As a result, the model is developed by assuming the combustion chamber of FPE as a homogeneous variable-volume reactor, in which the in-cylinder gases are ideally mixed from the beginning. During the simulation, only compression and expansion processes are considered, and scavenging process is neglected. Consequently, the simulation studies only focus on the combustion process within an engine cycle.

The entire model comprises three components: a unique mechanism synthesizing variable piston trajectories of FPE, a comprehensive physics-based model representing FPE operation, which is mainly developed via the first law of thermodynamics. At last, specific reaction mechanisms will also be investigated to reproduce the combustion process of 


\begin{tabular}{|l|l|}
\hline \multicolumn{1}{|c|}{ Symbol } & \multicolumn{1}{c|}{ Description } \\
\hline $\boldsymbol{A}_{\text {wall }}$ & Surface area of the combustion chamber \\
\hline $\boldsymbol{C}_{\boldsymbol{v}, \boldsymbol{i}}$ & Constant volume heat capacity of species $i$ \\
\hline $\boldsymbol{h}$ & Heat transfer coefficient \\
\hline $\boldsymbol{h}_{\boldsymbol{i}, \boldsymbol{m}}$ & Molar enthalpy of species $i$ \\
\hline $\boldsymbol{M}_{\boldsymbol{i}}$ & Molar weight of species $i$ \\
\hline $\boldsymbol{m}$ & The mass of in-cylinder air-fuel mixture \\
\hline $\boldsymbol{m}_{, \text {chem }}$ & Net production of species $i$ in mass-scale \\
\hline $\boldsymbol{N}_{\boldsymbol{s}}$ & Total number of species in reaction mechanism \\
\hline $\boldsymbol{P}$ & Pressure of in-cylinder gas \\
\hline $\boldsymbol{Q}_{\text {Chem }}$ & Heat release due to chemical reaction \\
\hline $\boldsymbol{Q}_{\boldsymbol{H} \boldsymbol{T}}$ & Heat loss through engine wall \\
\hline $\boldsymbol{R}_{\boldsymbol{m a s s}}$ & Equivalent gas constant of mixed in-cylinder gas \\
\hline $\boldsymbol{R}_{\boldsymbol{i}}$ & Gas constant of species $i$ \\
\hline $\boldsymbol{T}$ & Temperature of in-cylinder gas \\
\hline $\boldsymbol{T}_{\text {wall }}$ & Temperature of engine wall \\
\hline $\boldsymbol{U}$ & Internal energy of in-cylinder gas \\
\hline $\boldsymbol{V}$ & Combustion chamber volume \\
\hline $\boldsymbol{v}_{\boldsymbol{i}}$ & Net production of species $i$ in concentration scale \\
\hline $\boldsymbol{w}$ & Average in-cylinder gas velocity \\
\hline $\boldsymbol{\omega}_{\boldsymbol{i}}$ & Mass fraction of species $i$ \\
\hline
\end{tabular}

\subsection{Geometric Model}

The geometric model mainly describes the geometric structure of the FPE (Table.1). However, the most important function of this model is to represent variable piston trajectories in the FPE. Due to the absence of mechanical crankshaft, the piston in FPE owns more freedom compared to conventional ICE. This freedom enables FPE to vary both CR and piston motion patterns between the bottom dead center (BDC) and the top dead center (TDC) points, indicated by parameter $\Omega$, (Fig. 3). The detailed mechanism explaining how to synthesize these piston trajectories can be found in [26].

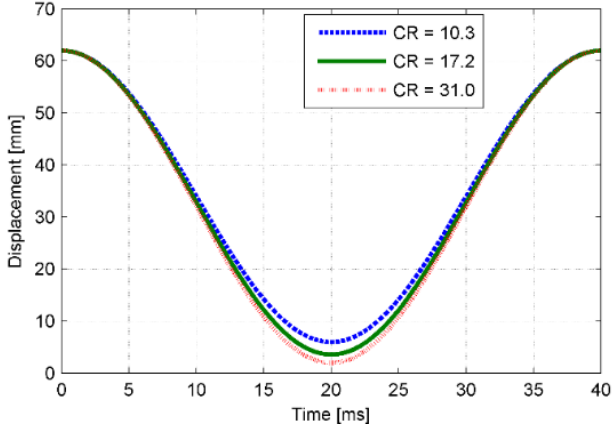

(a)

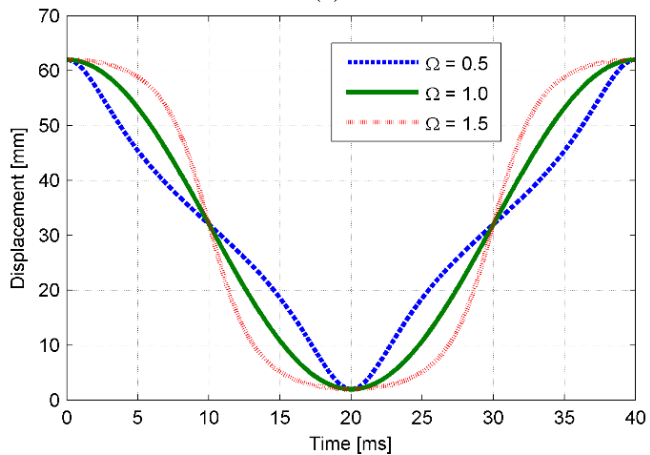

(b)
Furthermore, the piston trajectory can even be asymmetric (Fig. 4). These asymmetric trajectories actually realize in-cycle combustion control by assigning different control objectives while designing each trajectory section. For example, the compression process can be determined by optimizing the combustion phase, and the expansion process can be designed to reduce the related heat loss and NOx emission [27].

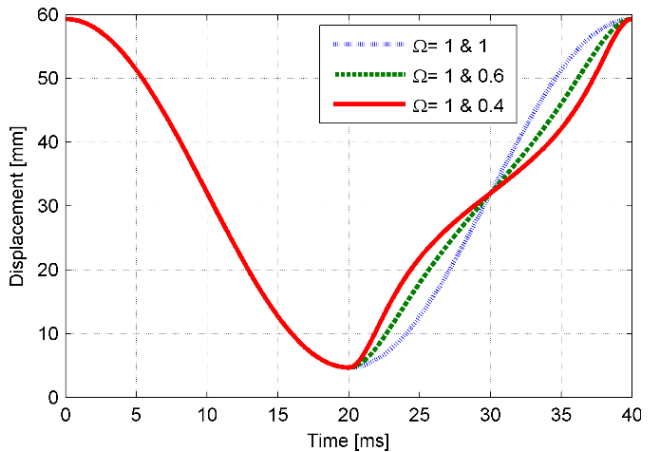

Figure 4. Asymmetric trajectories generated by the FPE.

\subsection{Physics-based Model}

The combustion chamber is modeled as a closed system. Related energy and species mass conservation equations are listed as below:

$$
\frac{d U}{d t}=-P \frac{d V}{d t}-\dot{Q}_{H T}+\dot{Q}_{\text {Chem }}
$$$$
m \frac{d \omega_{i}}{d t}=\dot{m}_{i, c h e m} \quad i=1,2 \ldots N_{s}
$$

The left term in (18), $d U / d t$, represents the time-derivative of internal energy. The three terms on the right side are volumetric work, heat loss, and chemical heat release, respectively.

In (19), $m$ is air-fuel mixture mass. $N_{s}$ is the total number of species in the reaction mechanism. $\omega_{i}$ represents the mass fraction of species $i$. Its right term is net production rate of species $i$ in mass-scale calculated by all the involved reactions.

More specifically, the heat loss term in (18) is derived via a convection model [46]:

$$
\dot{Q}_{H T}=h \cdot A_{\text {wall }}\left(T-T_{\text {wall }}\right)
$$

where $A_{\text {wall }}$ is the variable surface area of the chamber, $T_{\text {wall }}$ is the wall temperature, assumed as 500K [26] and $h$ is the heat transfer coefficient, determined via Woshini correlation [46]:

$$
h=3.26 \cdot b^{-0.2} P^{0.8} T^{-0.55} w^{0.8}
$$

where $b$ is the engine bore, which is $79.5 \mathrm{~mm}, P$ and $T$ are the pressure and temperature of the in-cylinder gas, and $w$ is the average in-cylinder gas velocity, which is set as $8 \mathrm{~m} / \mathrm{s}$ based on the FPE operation [26].

The ideal-gas law is also applied to calculate $d U / d t$, incylinder pressure $P$ and the equivalent gas constant of mixed in-cylinder gases $R_{\text {mass }}$. Several parameters are utilized during the calculation, which include in-cylinder temperature $T$, constant volume heat capacity of each species $C_{v, i}$, mass fraction of each species $\omega_{i}$, gas constant of each species $R_{i}$, total mass $m$ and chamber volume $V$ :

$$
\frac{d U}{d t}=\sum_{i=1}^{N_{s}} C_{v, i} \cdot m \cdot \omega_{i} \frac{d T}{d t}+\sum_{i=1}^{N_{s}} C_{v, i} \cdot m \cdot T \cdot \frac{d \omega_{i}}{d t}
$$




$$
\begin{gathered}
R_{\text {mass }}=\sum_{i=1}^{N_{s}} R_{i} \cdot \omega_{i} \\
P \cdot V=m \cdot R_{\text {mass }} \cdot T
\end{gathered}
$$

\subsection{Chemical Reaction Mechanisms}

A specific chemical reaction mechanism has to be implemented into the model to calculate the chemical-related terms in (18), (19) and (22) by providing thermal data of each species and the corresponding chemical kinetics:

$$
\begin{gathered}
\dot{Q}_{\text {Chem }}=-V \cdot \sum_{i=1}^{N_{s}} v_{i} \cdot h_{i, m} \\
m \frac{d \omega_{i}}{d t}=\dot{m}_{i, \text { hem }}=V \cdot M_{i} \cdot v_{i}
\end{gathered}
$$

where $v_{i}, M_{i}$ and $h_{i, m}$ represent the net production rate, molar weight and the molar enthalpy of species $i$ respectively.
A complete reaction mechanism usually includes two parts, namely the thermal data part and the chemical reactions part. The thermal data part offers thermodynamic properties of each species via the NASA polynomial parameterization. The chemical reactions part provides valuable information to calculate net production rate of species $i$, e.g. $v_{i}$ in (25) and (26).

A diagram of the model is presented in Fig. 5 in order to reflect its intrinsic dynamics more clearly. Typically, variable piston trajectories provide volumetric information to the other two. Meanwhile, the chemical reaction mechanism sends the thermal properties and the derived chemical states into the physical-based model, while the latter one offers $T, P$ and $w_{i}$ in return. Inside the physics-based model, the heat loss submodel provides the heat loss term to the thermal dynamics submodel after receiving $T$ and $P$.

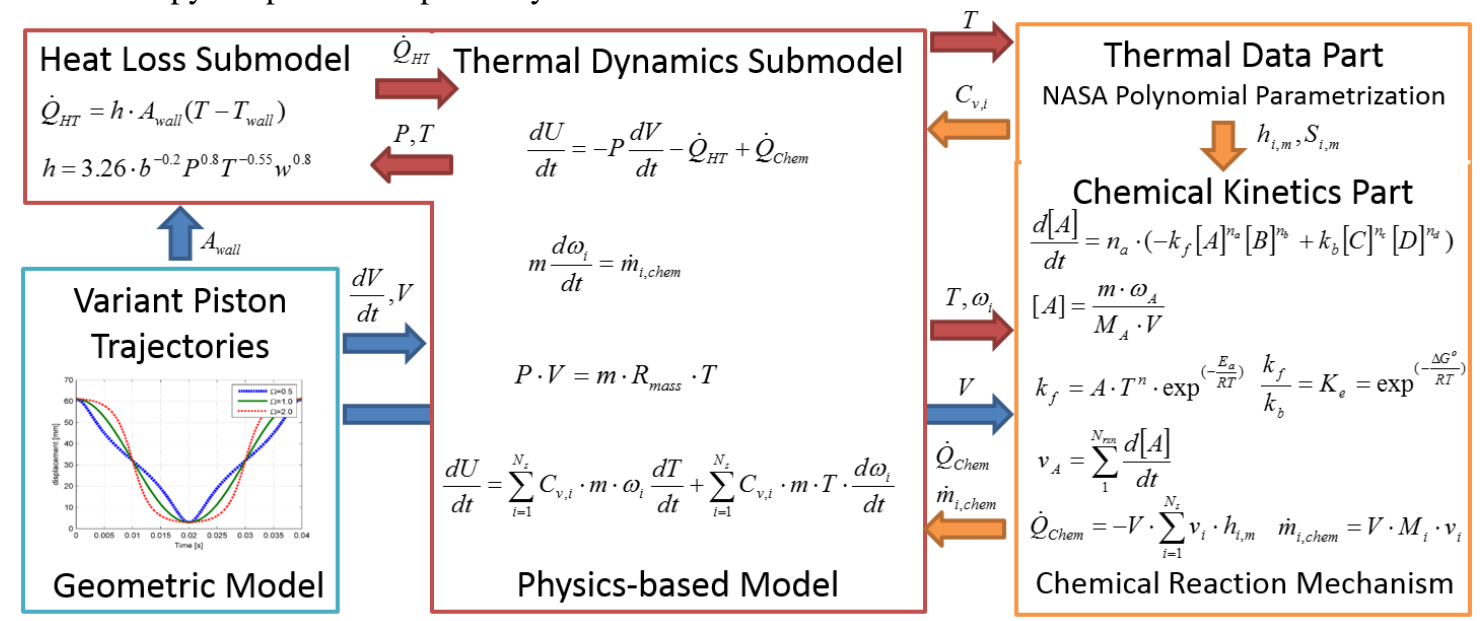

Figure 5. Diagram of the presented modeling approach [26]

Five reaction mechanisms are chosen and implemented into the developed model to represent the combustion processes of the key components within the selected renewable fuels. Two requirements affect this selection considerably: first of all, the selected mechanism must capture the essential feature of the chemical kinetics. On the top of that, the mechanism has to comprise a lowest permissible number of species and reactions, which improves computational efficiency significantly. The five reaction mechanisms are listed in Table.5. The effectiveness of all the reaction mechanisms, in terms of predictions of ignition delay time and flame propagation speed, have been experimentally validated by different facilities, e.g. shock tube, constant volume chamber and test-bed engine [47-50].

Table. 5 Selected reaction mechanisms for various renewable fuels

\begin{tabular}{|c|c|c|c|}
\hline Fuel & \# of species & \# of reactions & Mechanism \\
\hline Hydrogen & 53 & 325 & GRI-30 ${ }^{\mathrm{a}}$ \\
\hline Biogas & 53 & 325 & GRI-30 \\
\hline Syngas & 53 & 325 & GRI-30 \\
\hline Ethanol & 57 & 383 & LLNL $^{\mathrm{b}}$ Ethanol \\
\hline DME & 79 & 683 & LLNL DME, 2000 \\
\hline Biodiesel & 118 & 1178 & $\begin{array}{c}\text { LLNL C10 Methyl } \\
\text { Ester Surrogates }\end{array}$ \\
\hline
\end{tabular}

\begin{tabular}{c|c|c|c|} 
F-T fuel & 171 & 1620 & $\begin{array}{c}\text { U of Connecticut } \\
\text { PRF mechanism }\end{array}$ \\
$\begin{array}{c}\text { a: GRI-30 mechanism is mainly proposed by UC Berkeley } \\
\text { b: LLNL stands for Lawrence Livermore National Laboratory }\end{array}$ \\
?
\end{tabular}

\subsection{Modeling Tools}

Cantera is an open-sourced software package which is capable of executing the chemical, thermodynamic and kinetics calculation. In this research, it is used to integrate all the reaction mechanisms with the physical-based model [51]. All the simulations are conducted with Python 2.7 version at first. The derived outputs are then sent to Matlab R2012b for further processing and imaging.

\section{Simulation Results and Discussion}

The main focus of this study is to investigate the effects of the piston trajectory on the combustion process of different renewable fuels. In the FPE, the piston trajectories can be varied with respect to both $\mathrm{CR}$ and $\Omega$. By changing $\mathrm{CR}$, all seven selected fuels can be ignited in the simulation, which proves FPE's ultimate fuel flexibility. Furthermore, simulations of syngas and F-T fuels show that this freedom can also expand available range of fuel compositions. The FPE can even enhance the engine tolerance of fuel impurities by varying the $\mathrm{CR}$, proved by the simulation of DME and ethanol. 
In addition, the capability of varying $\Omega$ in the FPE enables the reduction of required CR to ignite renewable fuels, which is proved by both results of biogas and biodiesel. On top of that, the simulation results of DME also show that the freedom of $\Omega$ can be further utilized to optimize the combustion process at a fixed CR.

Afterward, the simulation of $\mathrm{H}_{2}$ is conducted, concentrated on the optimization of FPE operation by implementing asymmetric piston trajectories. Such asymmetric piston trajectories are designed based on the chemical kinetics of the fuel, variable loading conditions and corresponding NOx emission.

\subsection{Effects of CR}

$\mathrm{CR}$ is such an important parameter for ICE due to its significant influence on engine efficiency. In addition, some researchers even claimed that by changing $\mathrm{CR}$, almost any liquid fuels can be utilized in the ICE [22]. Different variable CR mechanisms have been proposed for ICE [22, 52]. Most of them modify the crank/connecting rod mechanism with mechanical linkages and actuation systems. Those technologies offer some flexibility for CR control, but still subject to the mechanical constraints and the response time of the actuation system.

FPE, however, offers continuously variable CR control with the assistance of the virtual crankshaft, and thus realizes the ultimate fuel flexibility. In other words, all renewable fuels can be employed into the FPE.

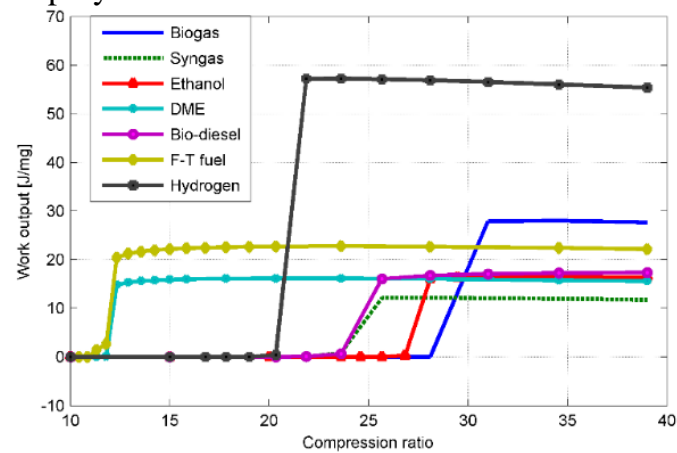
536
90\% methane, and F-T fuels are followed from this perspective. Fewer output works per mass are produced by DME, ethanol, and bio-diesel, partially because higher oxygen contents in their molecules. At last, syngas has the least energy density since it comprises more incombustible components, such as $\mathrm{CO}, \mathrm{CO}_{2}$ and a large amount of $\mathrm{N}_{2}$.

Besides, variable CR also enhances FPE's capability of dealing with different compositions of renewable fuel. For example, as mentioned in section 2.2, the compositions of the syngas can be varied significantly due to the moisture content of the feedstock, employed ER during gasification, gasification temperature and utilized gasification agent, as listed in Table. 7.

Table. 7 Typical compositions (in vol.) of various syngas under different conditions $[53,54]$

\begin{tabular}{cccccc}
\hline Conditions & $\mathbf{C O}$ & $\mathbf{H}_{\mathbf{2}}$ & $\mathbf{C H}_{\mathbf{4}}$ & $\mathbf{C O}_{\mathbf{2}}$ & $\mathbf{N}_{\mathbf{2}}$ \\
\hline Normal & 20 & 18 & 2 & 10 & 50 \\
\hline High ER & 10 & 9 & 1 & 15 & 65 \\
\hline High moist & 9 & 22 & 1 & 8 & 60 \\
\hline High T & 30 & 20 & 1 & 9 & 40 \\
\hline Oxygen agent & 45 & 35 & 6 & 14 & 0 \\
\hline
\end{tabular}

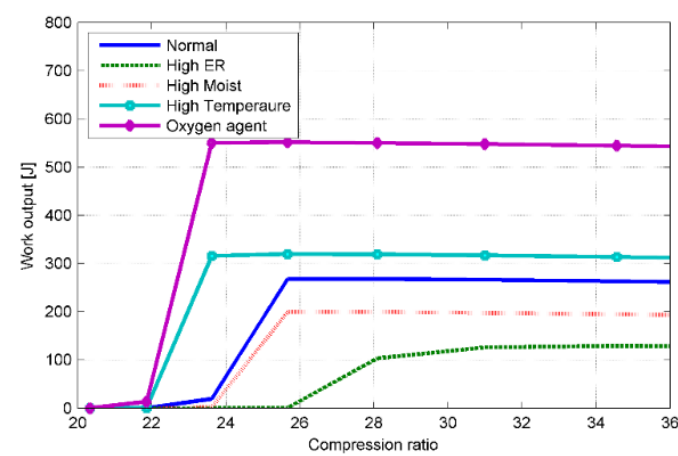

Figure 7. Work outputs vs different CR (syngas produced in different conditions, AFR $=2$, identical $\Omega=1$ )

Generally, if the gasification proceeds at a higher temperature or with pure oxygen agent, more combustible components, such as $\mathrm{CO}$ and $\mathrm{H}_{2}$, are produced. In this way, the syngas is easier to be ignited by compression and generates more output work as shown in Fig. 7. If the feedstock has a high content of moisture, more energy is consumed to evaporate the moisture before the gasification, which results in less yield of combustible components. At last, if high ER is employed, more biomass feedstock will be converted to completed products, such as $\mathrm{CO}_{2}$ and $\mathrm{H}_{2} \mathrm{O}$. Consequently, high CR is required to ignite such syngas and least output work is produced. The last two types of syngas are usually considered as non-combustible syngas for conventional ICE. [34] However, by varying the CR using the virtual crankshaft mechanism, the FPE can still ignite the last two types of syngas and produce output work, though its amount is still relatively low.

A similar trend can be achieved in F-T fuels, which is indicated by a combination of $\mathrm{n}$-heptane and iso-octane with different volume percentages respectively (Fig. 8). 


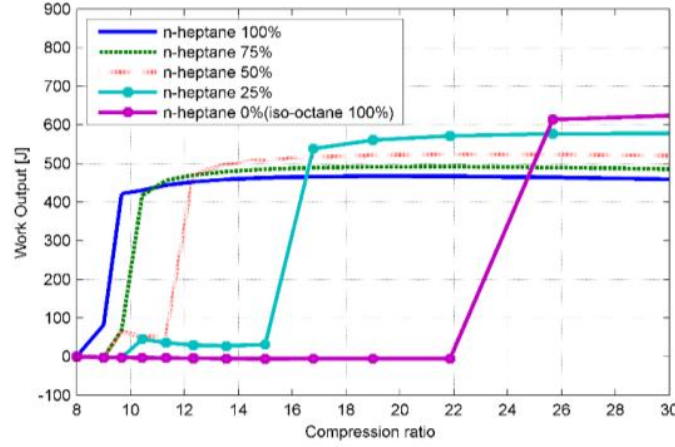

Figure 8 . Work output vs different CR (F-T fuels with different compositions, $\mathrm{AFR}=2$, identical $\Omega=1$ )

Besides large variation in compositions, the existences of impurities are also recognized as another roadblock preventing the wide application of renewable fuel. For instance, the production of DME usually generates methanol simultaneously. Complicated after-treatment processes are conducted aimed to remove methanol, which inevitably increases the price of DME. Another example is ethanol, which is completely miscible with water. Usually, multiple distillation processes are needed to dehydrate the produced ethanol in order to make it satisfying the requirement as a vehicle fuel.

Variable CR provides an effective method to increase the tolerance of undesired components in renewable fuels, as shown in Fig. 9 (DME case) and Fig. 10 (ethanol case) respectively.

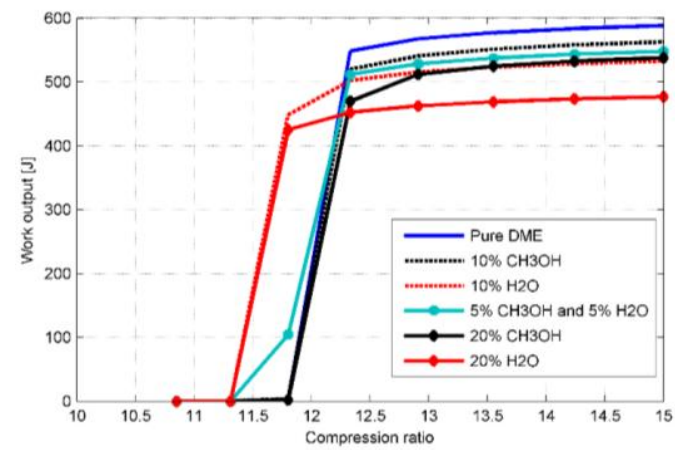

Figure 9. Work output vs different CR (DME with different impurities, AFR = 2 , identical $\Omega=1$ )

As can be seen in Fig. 9, no matter how many methanol and water are contained in DME (within $20 \%$ impurities), the FPE can always trigger the combustion by providing a suitable $\mathrm{CR}$. Compared to the current purity requirement of DME using in the ICE (usually 95 98\% in vol.) [55], such large tolerance of fuel impurity enhances the application of DME and reduces the corresponding cost. However, less work output is indeed a problem, when a larger amount of water and/or methanol exists in DME.

It may be surprised at the first glimpse that smaller CR is required to ignite DME with water. However, this phenomenon can be explained since more reactive radicals, such as $\mathrm{H}, \mathrm{O}$, and $\mathrm{OH}$, are generated from $\mathrm{H}_{2} \mathrm{O}$ during the ignition process. A similar trend can be observed in ethanol case as well (Fig. 10). These results offer unintuitive insights for renewable fuel production. It seems that there is no need to completely dehydrate the final products, since an appropriate amount of water inside fuel can somewhat improve the ignition and reduce the requirement for after treatment.

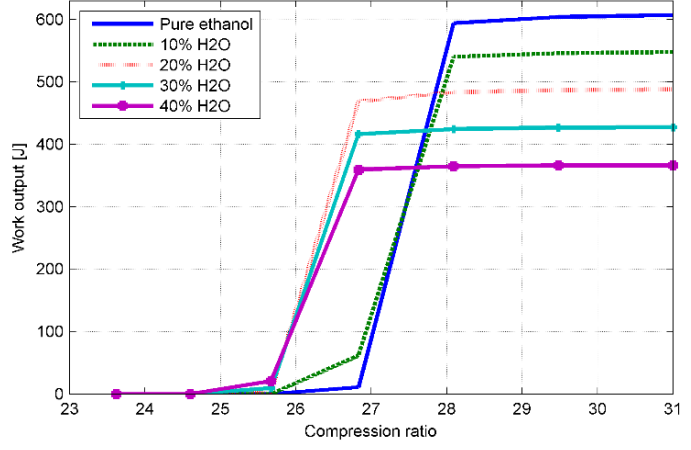

601

602
Figure 10. Work output vs different CR (ethanol with different water contents, AFR $=2$, identical $\Omega=1$ )

In a sum, the capability of varying CR possessed by FPE not only offers FPE ultimate fuel flexibility, but also reduces the refinement requirements for those renewable fuels Consequently, a co-optimization can be achieved. On one hand, the production of renewable fuels can be optimized by taking their chemical and physical properties, environmental impact, and related economy influence into a full consideration. On the other hand, an optimal CR can always be designed and implemented into the FPE to fully leverage the utilization of the employed renewable fuel.

\subsection{Effects of $\Omega$}

The minimal required CRs in Table. 6 are derived only according to chemical kinetics. However, it is possible that those CR are still too high that the FPE cannot sustain a longterm operation due to the mechanical strength of engine material. Besides, high CR condition also adversely impacts engine's NVH behavior. As a result, the FPE is expected to operate at the lowest permissible CR.

The FPE provides another degree of freedom on piston trajectory to further reduce the CR listed in Table. 6. With the virtual crankshaft, the piston motion pattern between the TDC and BDC points, indicated by $\Omega$, can also be varied to realize this function. An example of biogas is shown in Fig. 11.

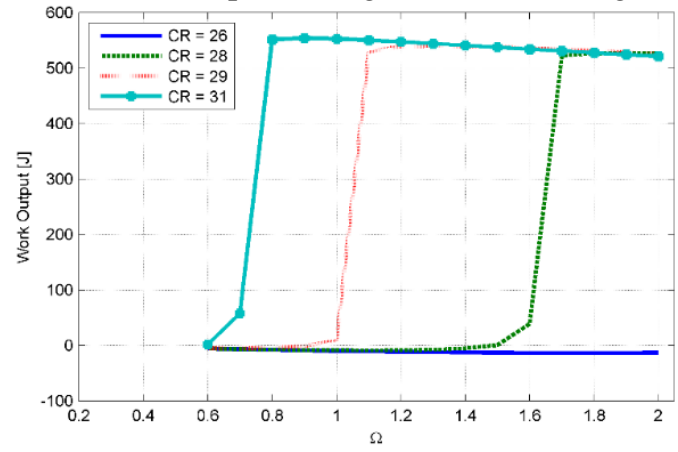

Figure 11. Work output vs different $\Omega$ (biogas, AFR $=2$ )

It is clearly from Fig. 11 that by increasing $\Omega$, the ignition of biogas can be achieved at $\mathrm{CR}=28$, rather than $\mathrm{CR}=31$ as listed in Table. 6. The result is even more impressive compared to conventional HCCI engines for upgraded biogas, of which CR is usually in the range of $30 \sim 40$ [15]. This reduction can be explained via Fig. 3(b). Obviously, larger $\Omega$ represents a longer period of piston locating around the TDC point. As a result, even though the $\mathrm{CR}$ is smaller, the longer period for piston staying around the TDC point still guarantees the accumulation of sufficient radical species to trigger the chain reaction mechanism and thus ignite the air-fuel mixture. 
640 A similar trend is obtained in biodiesel case. As shown in Fig.

64112 , the required minimal CR is reduced from 25 to 22.

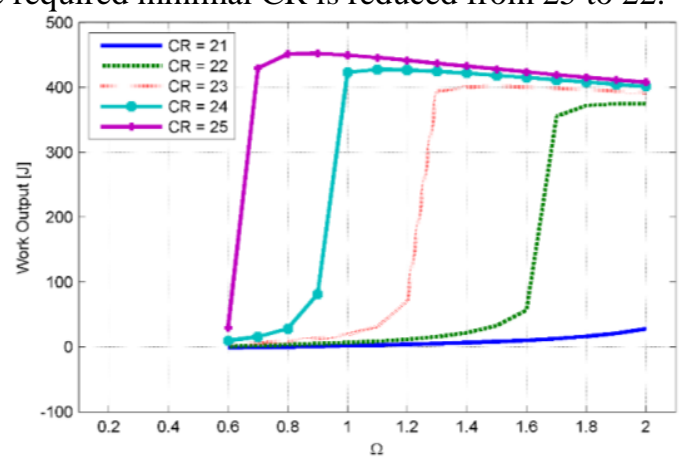

Figure 12. Work output vs different $\Omega$ (biodiesel, AFR $=2$ )

On the other hand, the ability to vary $\Omega$ in the FPE can also benefit the combustion itself at a fixed CR.

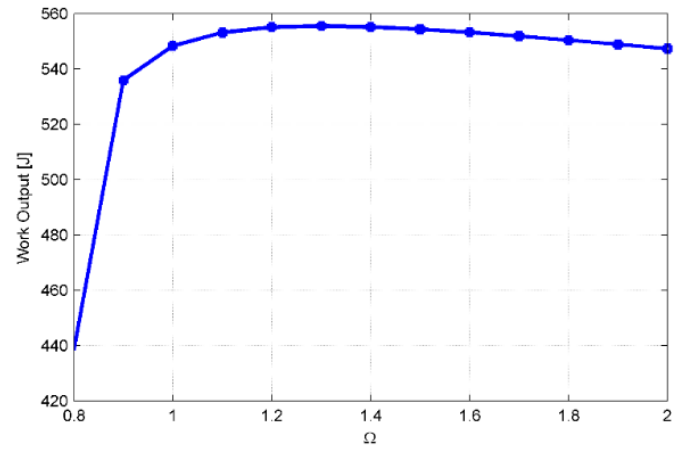

Figure 13. Work output vs different $\Omega(\mathrm{DME}, \mathrm{AFR}=2, \mathrm{CR}=12)$

Fig. 13 shows the combustion of DME along different piston trajectories with distinct $\Omega$ but identical $\mathrm{CR}=12$. Obviously, the optimal $\Omega$ under this $\mathrm{CR}$ is 1.3 , which produces $555.57 \mathrm{~J}$ output work at about $49.3 \%$ thermal efficiency. In addition, similar simulation is also conducted using piston trajectory of conventional ICE at same CR. The corresponding thermal efficiency is $44.5 \%$, which agrees the results reported in [56]. In this case, the variable $\Omega$ in the FPE enables about 5\% improvement on thermal efficiency. It is worth noting that at higher $\mathrm{CR}$, the improvement of thermal efficiency achieved by this freedom will be further enhanced, as shown in [26].

\subsection{Asymmetric piston trajectory}

The most appealing advantage of the trajectory-based combustion control is that the implemented trajectory can even be asymmetric. In this way, two control objectives can be assigned to piston trajectory separately. For instance, the compression trajectory can be designed to optimize the combustion phasing. The expansion trajectory can be determined to reduce NOx emission. An example of $\mathrm{H}_{2}$ is illustrated in Fig. 14 and Fig. 15. In this example, each asymmetric piston trajectories are described by two $\Omega \mathrm{s}: \Omega_{\text {comp }}$ represents the $\Omega$ of compression trajectories and $\Omega_{\exp }$ shows the value along expansion process.

Fig. 14 shows the corresponding output work along different asymmetric piston trajectories. As can be seen, if $\Omega_{\text {comp }}$ is too small, a specific $\Omega_{\text {exp }}$ is required to ignite the $\mathrm{H}_{2}$. For example, if $\Omega_{\text {comp }}$ is as small as 0.6 , the minimal required $\Omega_{\exp }$ is 1.2 , reflected by the blue line in Fig. 14(a). On the other hand, if $\Omega_{\text {comp }}$ is large enough $(\geq 1.4)$, any $\Omega_{\exp }$ in the range of 0.6 to 2.0 can be implemented to trigger the combustion. The above results can be explained by the relationship between the $\Omega$ and the duration while piston locating around the TDC. Any trajectory with $\Omega_{\text {comp }}$ larger than 1.4 already provides enough time for ignition while the piston locating around the TDC point along the compression process. Consequently, a quick expansion can be implemented afterwards to reduce the heat loss by selecting the smallest $\Omega_{\text {exp }}$ available. To the contrary, if $\Omega_{\text {comp }}$ is too small to provide enough time for ignition, the subsequent $\Omega_{\exp }$ has to be increased to trigger the combustion.

In addition, as long as the combustion is triggered successfully, the amounts of output works are very close to each other, as shown in Fig. 14(a). Specifically, the variation is within $25 \mathrm{~J}$ in the entire $\Omega$ domain. Fig. 14(b) is a zoomed-in view, which illustrates the output works more clearly. Obviously, the maximal output work is achieved when $\Omega_{\text {comp }}=$ 1.8 and $\Omega_{\exp }=0.6$, of which output work is $522.81 \mathrm{~J}$, with $55.9 \%$ thermal efficiency. To compare, the simulation is also repeated using the ICE's trajectory. The later result turns out that the combustion cannot occur in this situation. In addition, a study, investigating the HCCI combustion in a FPE with uncontrollable pistons, claimed that $48 \%$ thermal efficiency is achieved when the engine was powered by $\mathrm{H}_{2}$ and operated at similar CR [15]. As a result, by using the designed asymmetric piston trajectory, almost $8 \%$ improvement on thermal efficiency can be achieved. However, the derived asymmetric trajectory $\left(\Omega_{\text {comp }}=1.8, \Omega_{\exp }=0.6\right)$ may still not be the optimal one, if NOx emission is taken into account.

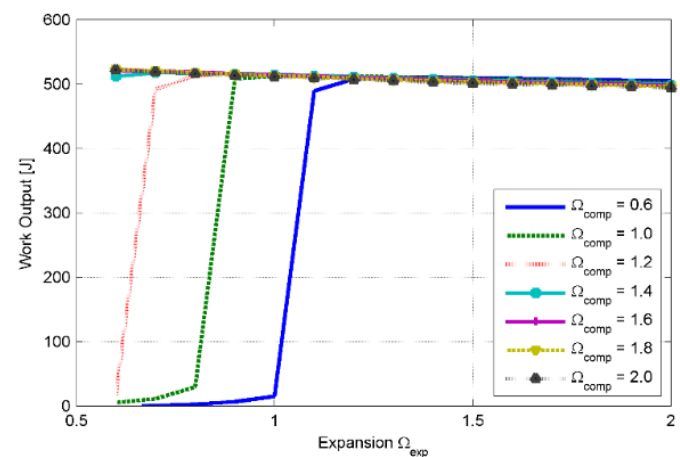

(a)

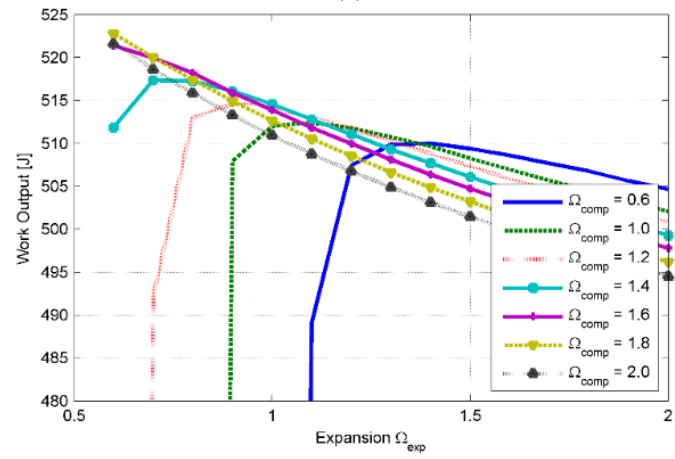

(b)

Figure 14. Work output along asymmetric piston trajectories, indicated by two $\Omega \mathrm{s}\left(\mathrm{H}_{2}, \mathrm{AFR}=2, \mathrm{CR}=22\right.$, (b) is the zoom-in view of (a))

NOx emission is such a critical aspect due to the increasingly public concerns on the environment. Fig. 15 represents the corresponding NOx emission following the same setup in Fig. 14. As can be seen, the NOx emissions of all the simulation cases are within the range of 30 to $140 \mathrm{ppm}$, which are significantly less than typical range of NOx 
emission, 100 to $500 \mathrm{ppm}$, in the conventional engine (almost $70 \%$ reduction) $[15,57]$. Usually, the smallest NOx emission is achieved by the smallest available $\Omega_{\text {exp }}$. Those trajectories provide quickest expansion, and therefore reduce in-cylinder temperature immediately and freeze the NOx production reactions [58].

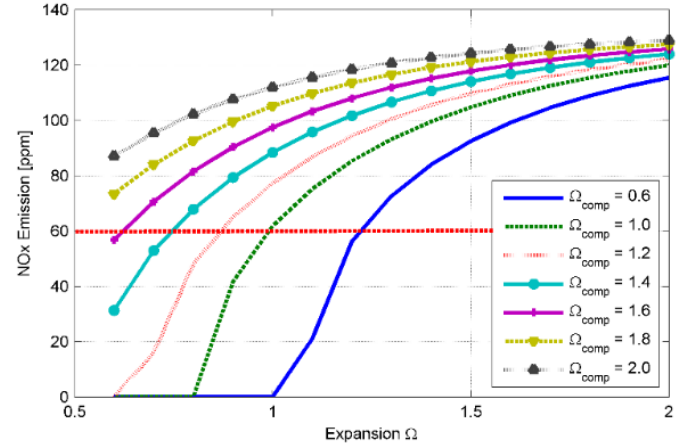

Figure 15. NOx emission along asymmetric piston trajectories, indicated by two $\Omega \mathrm{s}\left(\mathrm{H}_{2}, \mathrm{AFR}=2, \mathrm{CR}=22\right)$

As a result, the final optimal $\Omega$ pair has to be determined by considering both effects of output work and NOx emission. For instance, the aforementioned $\Omega$ pair $\left(\Omega_{\text {comp }}=1.8, \Omega_{\exp }=\right.$ $0.6)$, even though it produces the maximal output work, cannot be selected if the NOx emission is required to be less than 60 ppm. Thus, the optimal $\Omega$ pair should be $\Omega_{\text {comp }}=1.6$ and $\Omega_{\exp }$ $=0.6$, which produces $56.82 \mathrm{ppm}$ NOx emission and slightly less output work, which is $521.39 \mathrm{~J}$ at $55.7 \%$ thermal efficiency. The corresponding optimal asymmetric piston trajectory, in-cylinder temperature profile, P-V diagram, and NOx production are shown in Fig. 16.
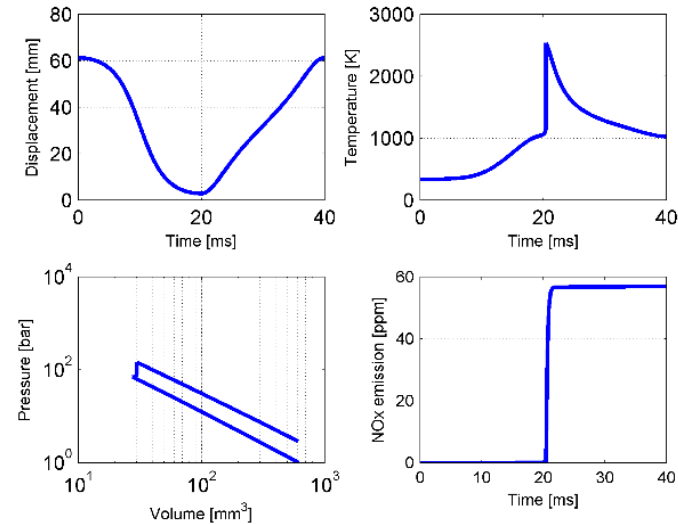

Figure 16. Combustion performance along piston trajectory $\Omega_{\text {comp }}=1.6, \Omega_{\exp }$ $=0.6,\left(\mathrm{H}_{2}, \mathrm{AFR}=2, \mathrm{CR}=22\right)$

Certainly, the derived optimal $\Omega$ pair should be adjusted according to CR. For example, if the CR is increased from 22 to 24 for the same setup in Fig. 14 and Fig. 15, the corresponding optimal $\Omega$ pair is then varied to $\Omega_{\text {comp }}=0.6$, $\Omega_{\exp }=0.6$, as can be seen in Fig. 17. Intuitively, specific optimal asymmetric piston trajectories can also be generated for other renewable fuels.

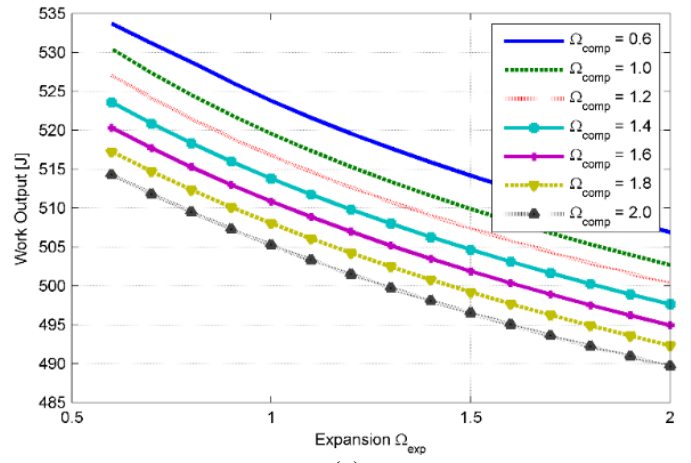

(a)

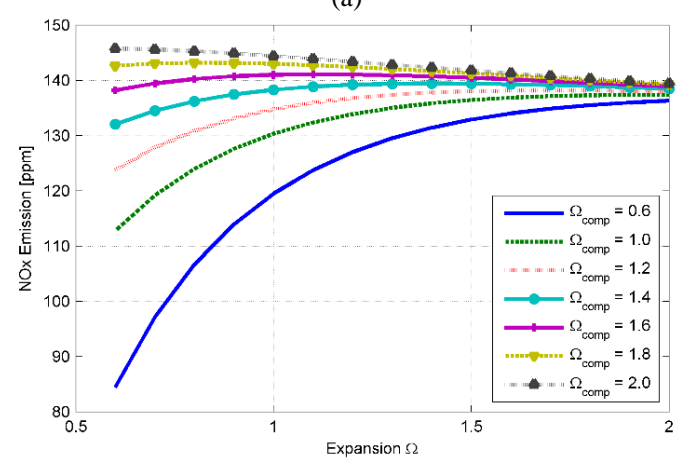

(b)

Figure 17. Combustion performance along asymmetric piston trajectories, indicated by two $\Omega \mathrm{s}\left(\mathrm{H}_{2}, \mathrm{AFR}=2, \mathrm{CR}=24\right.$, (a) output work (b) NOx emission)

In summary, the controllable piston trajectory in the FPE is able to extract the chemical energy from the renewable fuels in an effective and clean manner. Such asymmetric piston trajectories are very difficult to realize in conventional ICEs. However, it is easy to achieve in the FPE with the assistance of the virtual crankshaft mechanism, by designing an appropriate trajectory reference accordingly. The above results show that by applying the optimal asymmetric piston trajectories, the thermal efficiency of the FPE is enhanced significantly, while the NOx emission can be reduced simultaneously. Furthermore, the virtual crankshaft also enables real-time control of the piston motion. In this way, the optimal asymmetric piston trajectory can even be modified according to the load variation in real time.

\section{Conclusion}

In this paper, the trajectory-based combustion control, enabled by the FPE with the virtual crankshaft mechanism, is applied to renewable fuels. Seven renewable fuels, e.g. hydrogen, biogas, syngas, ethanol, DME, biodiesel, and F-T fuels are considered herein. The results show that the FPE has the ultimate fuel flexibility. In addition, a suitable CR can also be selected not only to guarantee the ignition, but also to widen the tolerance of undesired composition in renewable fuels. Furthermore, an appropriate piston motion pattern between the two dead centers can also be determined to reduce the required $\mathrm{CR}$ for each renewable fuel and to further enhance engine efficiency (5\% improvement in DME case). At last, optimal asymmetric piston trajectory can be designed for specific renewable fuels, which enables a significant reduction on the NOx emission (70\% reduction in $\mathrm{H}_{2}$ case) and an improvement on the thermal efficiency $(8 \%$ improvement in $\mathrm{H}_{2}$ case) simultaneously. 
In summary, the trajectory-based combustion control realizes the co-optimization of fuels and engine operation. Within this context, the production of utilized fuels, no matter renewable or traditional, can be optimized from the perspectives of their own physical and chemical properties, environment impacts and economical costs. Subsequently, the engine operation can also be optimized by implementing an optimal piston trajectory into the FPE, which is synthesized according to specific characteristics of the utilized fuel, variable loading requirements, and stringent emission regulation.

In the future, a multi-zone model will be developed to take into account the inhomogeneity inside the combustion cylinder. The effect of this combustion control on the production of other emissions, such as $\mathrm{CO}$, unburned $\mathrm{HC}$ and PM can then be evaluated. Moreover, advanced controloriented models will be developed and rigorous optimization method will be integrated to achieve both off-line and on-line optimization in terms of maximal engine efficiency and minimal emissions production.

\section{Acknowledgement}

The work is supported in part by NSF under grant CMMI1634894

\section{References}

[1] The U.S. Department of Energy, "Quadrennial Technology Review: an Assessment of Energy Technologies and Research Opportunities", September 2015.

[2] Bhutto, A. W., Qureshi, K., Abro, R., Harijan, K., Zhao, Z., Bazmi, A. A., Abbas, T. and Yu, G., "Progress in the Production of Biomass-toliquid Biofuels to Decarbonize the Transport Sector - Prospects and Challegnes", Royal Society of Chemistry Advances, issue. 6, pp. 3214032170. 2016.

[3] International Energy Agency, "Energy Climate and Change: World Energy Outlook Special Report", Paris, France, 2015.

[4] Ribeiro, S. K., Kobayashi, S., Beuthe, M., Gasca, J., Greene, D., Lee, S. D., Muromachi, Y., Newton, P. J., Plotkin, S., Sperling, D., Wit, R. and Zhou, P. J. "Transport and its infrastructure", Cambridge, United Kingdom and New York, NY, USA, 2007.

[5] Guo, M., Song, W. and Buhain, J., "Bioenergy and Biofuels: History, Status, and Perspective", Renewable and Sustainable Energy Reviews, vol. 42, pp. 712-725, 2015.

[6] Sadeghiezhad, E., Kazi, S. N., Sadeghinejad, F., Badarudin, A., Mehrali, M., Sadri, R. and Safaei, M., "A Comprehensive Literature Review of Bio-fuel Performance in Internal Combustion Engine and Relevant Costs of Involvement", Renewable and Sustainable Energy Reviews, vol. 30, pp. 29-44, 2014.

[7] Bergthorson, J. M. and Thomson, M. J., "A Review of the Combustion and Emissions Properties of Advanced Transportation Biofuels and Their Impact on Existing and Future Engines", Renewable and Sustainable Energy Reviews, vol. 42, pp. 1393-1417, 2015.

[8] Sangeeta, S. M., Pande, M., Rani, M., Gakhar, R., Sharma, M., Rani, J. and Bhaskarwar, A. N., "Alternative fuels: an Overview of Current Trends and Scope for Future", Renewable and Sustainable Energy Reviews, vol. 32, pp. 697-712, 2014.

[9] Salvi, B. L., Subramanian, K. A. and Panwar, N. L., "Alternative Fuels for Transpiration Vehicles: a Technical Review", Renewable and Sustainable Energy Reviews, vol. 25, pp. 404-419, 2013.

[10] Agarwal, A. K., "Biofuel (Alcohols and Biodiesel) Applications as Fuels for Internal Combustion Engine", Progress in Energy and Combustion Science, vol. 33, pp. 233-271, 2007.

[11] Demirbas, A., "Progress and Recent Trends in Biofuels", Progress in Energy and Combustion Science, vol. 33, pp. 1-8 2007.

[12] Sanchez, O. and Cardona, C. A., "Trends in Biotechnological Production of Fuel Ethanol form Different Feedstock", Bioresource Technology vol. 99 pp. 5270-5295 2008.

[13] Sadeghinezhad, E., Kazi, S. N., Badarudin, A., Oon, C. S., Zubir, M. N.
M. and Mehrali, M., "A Comprehensive Review of Bio-diesel as Alternative Fuel for Compression Ignition Engines", Renewable and Sustainable Energy Reviews, vol. 28, pp. 410-424, 2013.

[14] Mikalsen, R. and Roskilly, A. P., "A Review of Free-piston Engine History and Applications", Applied Thermal Engineering, Vol.27, Issue.14-15, pp.2339-2352, Oct 2007.

[15] Van Blarigan, P., Paradiso, N. and Goldsborough, S., "Homogeneous Charge Compression Ignition with a Free Piston: A New Approach to Ideal Otto Cycle Performance", SAE Technic Paper 982484, Oct. 1998.

16] Somhorst, H. E. and Achten, P. J., "The Combustion Process in a DI Diesel Hydraulic Free Piston Engine", SAE Transaction, Vol.105, 1996.

17] Kosaka, H., Akita, T., Moriya, K., Goto, S., Hotta, Y., Umeno, T. and Nakakita, K., "Development of Free Piston Engine Linear Generator System Part 1 - Investigation of Fundamental Characteristics", SAE Technical Paper 2014-01-1203, Apr. 2014.

18] Goto, S., Moriya, K., Kosaka, H., Akita, T., Hotta, Y., Umeno, T. and Nakakita, K., "Development of Free Piston Engine Linear Generator System Part 2 - Investigation of Control System for Generator", $S A E$ Technical Paper 2014-01-1193, 2014.

19] Li, K., Sadighi, A. and Sun, Z., "Active Motion Control of a Hydraulic Free Piston Engine", IEEE/ASME Transaction. Mechatronics, Vol. 19, Issue. 4, pp. 1148-1159, Aug, 2014

[20] Li, K., Zhang, C. and Sun, Z., "Precise Piston Trajectory Control for a Free Piston Engine", Control Engineering Practice, Vol. 34, pp. 30-38, Jan 2015.

[21] Jia, B., Tian, G., Feng, H., Zuo, Z. and Roskilly, A. P., "An Experimental Investigation into the Starting Process of Free-piston Engine Generator", Applied Energy, Vol. 157, pp. 798-804, 2015.

[22] Christensen, M., Hultqvist, A. and Johansson, B., "Demonstrating the Multi-Fuel Capability of a Homogeneous Charge Compression Ignition Engine with Variable Compression Ratio", SAE transactions, vol.108, no. 3, pp. 2099-2113, 1999

[23] Mikalsen, R. and Roskilly, A. P., "The Control of a Free-piston Engine Generator. Part 1: Fundamental Analyses", Applied Energy, Vol. 87, Issue. 4, pp. 1273-1280, 2010.

[24] Mikalsen, R. and Roskilly, A. P., "The Control of a Free-piston Engine Generator. Part 2: Engine Dynamics and Piston Motion Control", Applied Energy, Vol. 87, Issue. 4, pp. 1281-1287, 2010.

[25] Jia, B., Zuo, Z., Feng, H., Tian, G., Smallbone, A. and Roskilly, A. P., "Effect of Closed-loop Controlled Resonance Based Mechanism to Start Free Piston Engine Generator: Simulation and Test Results", Applied Energy, Vol. 164, pp. 532-539, 2016.

[26] Zhang, C., Li, K. and Sun, Z., "Modeling of Piston Trajectory-based HCCI Combustion Enabled by a Free Piston Engine", Applied Energy, vol. 139, pp. 313-326, 2015.

27] Zhang, C. and Sun, Z., "Using Variable Piston Trajectory to Reduce Engine-out Emissions", Applied Energy, vol. 170, pp. 403-414, 2016.

[28] Kalinci, Y., Hepbasli. A. and Dincer, I., "Biomass-based Hydrogen Production: A Review and Analysis," International Journal of Hydrogen Energy, vol. 34, pp. 8799-8817, 2008

29] Kirtay, E., "Recent Advances in Production of Hydrogen from Biomass", Energy Conversion and Management, vol. 52, pp. 1778-1789, 2011.

[30] Poschl, M., Ward, S. and Owende, P., "Evaluation of Energy Efficiency of Various Biogas Production and Utilization Pathways", Applied Energy, vol. 87, pp. 3305-3321, 2010.

[31] The U.S. Department of Energy, "What is Biogas", April, 2010.

[32] European Biomass Association, “A Biogas Road Map for Europe”, Jun, 2010.

33] German Biogas Association, "Biogas Segment Statistic 2014/2015", Nov. 2015.

[34] International Energy Agency, "Biogas Upgrading to Vehicle Fuel Standards and Grid Injection", Dec, 2006.

[35] Asadullah, M., "Barriers of Commercial Power Generation Using Biomass Gasification Gas: A Review", Renewable and Sustainable Energy Reviews, vol. 29, pp. 201-215, 2014.

[36] Martinez J. D., Mahkamov, K., Andrade, R. and Silva Lora, E. E., "Syngas Production in Downdraft Biomass Gasifiers and its Application using Internal Combustion Engine", Renewable Energy, vol. 38, pp, 1-9, 2012.

[37] Tinaut, F. V., Melgar, A., Horrillo, A. and de la Rose, A. D., "Method for Predicting the Performance of an Internal Combustion Engine Fuelled by Producer Gas and other Low Heating Value Gases", Fuel Processing Technology, vol. 87, pp. 135-142, 2006.

[38] Sridhar, G., Sridhar, H. V., Dasappa, S., Paul, P. J., Rajan, N. K. S. and Mukunda, H. S., "Development of Producer Gas Engine “, Proceeding 
of the Institution of Mechanical Engineers, Part D: Journal of Automobile Engineering, vol. 219, pp. 423-438, 2005.

[39] Balat, M. and Balat, H., "Recent Trends in Global Production and Utilization of Bio-ethanol Fuel", Applied Energy, vol. 86, pp. 2273-2282, 2009.

[40] Hahn-Hagerdal, B., Galbe, M., Gorwa-Grauslund, M. F., Liden, G. and Zacchi, G., "Bio-ethanol - the Fuel of Tomorrow from the Residues of Today", Trends in Biotechnology, vol. 24, issue. 12, pp. 549-556, 2006.

[41] The U. S. Energy Information Administration, "Monthly Biodisel Production Report", 2014.

[42] Ma, F. and Hanna, M. A., "Biodiesel Production: A Review", Bioresource Technology, vol. 70, pp. 1-15, 1999.

[43] Lapuerta, M., Armas, O. and Rodriguez-Fernandez, J., "Effect of Biodiesel Fuels on Diesel Engine Emissions", Progress in Energy and Combustion Science, vol. 34, pp. 198-223, 2008.

[44] Schulz, H., "Short History and Present Trends of FT Synthesis", Applied Catalysis A General, vol. 186, pp. 1-16, 1999.

[45] Wilhelm, D. J., Simbeck, D. R., Karp, A. D. and Dickenson, R. L., "Syngas Production for Gas-to-liquids Applications: Technologies, Issues and Outlook", Fuel Processing Technology, vol. 71, pp. 139-148, 2001.

[46] J. Heywood, (1988). Internal Combustion Engine Fundamentals, McGraw-Hill

[47] Gregory P. Smith, David M. Golden, Michael Frenklach, Nigel W. Moriarty, Boris Eiteneer, Mikhail Goldenberg, C. Thomas Bowman, Ronald K. Hanson, Soonho Song, William C. Gardiner, Jr., Vitali V. Lissianski, and Zhiwei Qin http://www.me.berkeley.edu/gri_mech/

[48] Kaiser, E. W., Wallington, T. J., Hurley, M. D., Platz, J., Curran, H. J. Pitz, W. J. and Westbrook, C. K., "Experimental and Modeling Study of Premixed Atmospheric-Pressure Dimethyl Ether-Air Flames", Journal of Physical Chemistry A, vol. 104, no.35, pp. 8194-8206, 2000.

[49] Marinov, N. M., "A Detailed Chemical Kinetic Model for High Temperature Ethanol Oxidation", International Journal Chemical. Kinetics, vol.31, pp. 183-220, 1999.

[50] Herbinet, O., Pitz, W. J. and Westbrook, C. K., "Detailed Chemical Kinetic Mechanism for the Oxidation of Biodiesel Fuels Blend Surrogate", Combust and Flame, vol. 157, issue. 5, pp. 893-908, 2010.

[51] Goodwin, D., Malaya N. and Speth. R., "Cantera: An Object-oriented Software for Chemical Kinetics, Thermodynamics and Transport Processes", available at https://code.google.com/p/cantera/.

[52] Ozawa, G., "Variable Compression Ratio Engine", U.S. Patent 5,682,854, 1997

[53] Asadullah, M., "Barriers of Commercial Power Generation Using Biomass Gasification Gas: A Review", Renewable and Sustainable Energy Reviews, vol. 29, pp. 201-215, 2014

[54] Puig-Arnavat, M., Bruno, J. C. and Coronas, A., "Review and Analysis of Biomass Gasification Models", Renewable and Sustainable Energy Reviews, vol. 14, pp. 2841-2851, 2010.

[55] ASTM international standard specification for dimethyl ether for fuel purpose ASTM D7901.

[56] Komnions, N. P. and Rakopoulos, C. D., "Modeling HCCI Combustion of Biofuels: A Review", Renewable and Sustainable Energy Reviews, vol. 16, pp. 1588-1610, 2012.

[57] DieselNet Technology Guide, "What Are Diesel Emissions", available at https://www.dieselnet.com/tech/emi_gas.php.

58] Zeldovich, Y. B., Sadovnikov, P, Y. and Frank-kamenetskii, D. A., "Oxidation of Nitrogen in Combusiton", Academy of Sciences of USSR, Institute of Chemical Physics, Moscow-Leningrad, 1947. 